\title{
A risk based approach for the assessment of natural hazards in the UAE
}

\author{
Haitham Saleh Alsenaani \\ Federal Authority For Nuclear Regulation (FANR) \\ E-mail: Tornados98@hotmail.com
}

\begin{abstract}
Civil developments have raised the necessity for conducting natural hazards risk assessment. This study employs the method of risk matrix applied on natural hazards for seismic, flooding and tsunami. In addition to the former hazards, Dust-Sand Storms "DSS" and climate change have been assessed in a form of context discussion. DSS assessment in particular is a vital element in terms of evaluating the natural hazards. This issue is unique and site specific for the UAE. The screening of a variety of information from different advanced countries identified that they do not consider DSS within their risk assessments. This study has been conducted using mainly the risk matrix as the primary assessment tool combining the probability of occurrences and severity.

Several risk matrices are developed to accumulate all historical, scientific and other global data that is used for the comparison of risk levels between the UAE and the rest of the world. In this work, the susceptibility of regions to natural hazards has been taken into account under the aspects of historical events recorded with respect to the geographical location. Vulnerable regions are represented through hazard maps as a result of the risk assessment. The overall outputs show encouraging results in some regions of the UAE. Although the assessment presents lower risk regions, it should be emphasized that minimizing the uncertainty by acquiring more historical data is required.
\end{abstract}

\section{Introduction}

The United Arab Emirates UAE consists of seven emirates with total area of 83,600 sq.km. The hazards discussed in this study will cover the following subjects:

1) Tsunami.

2) Flooding.

3) Sand/Dust storms.

4) Climate Change \& Flooding.

The reason for selecting the former hazards is because of their significant impact on the big developments. The aim of hazard analysis is to evaluate the nature of the hazards in order to obtain firm and verifiable results. This can be achieved by analyzing the probability of occurrences and severity within specified regions. The selected method employs all the sources discussed in the study where the susceptibility of the region is assessed rather than the hazard itself. Various methods and sources of information have been introduced for the assessment of natural hazards. This study looks for illustration of the hazards in the form of risk assessment to provide a comprehensive and technical research report highlighting key aspects of natural hazard. Several types of information can be injected into the risk matrix and then can be presented in the form of hazards maps. Some other hazards in this paper will be discussed in conceptual forms.

\section{Literature review}

This section gathers reports and researches published in relation to the study. UAE is exposed to number of natural hazards since the environment in the UAE is unique. Historically, there is one report of a tsunami occurring within the Gulf in 1008 A.D, but this event is doubtful. Most of the events build up with small scales due to storm surge which cannot be validated as tsunamis. The geographical characteristics of the Gulf region are described as shallow in depth and lack of historical tsunamis which makes the tsunami occurrence possibility in the gulf very unlikely [5]. There is 
potential for seismic activities in the UAE and in the Zagros mountains which are located South of Iran. In general, the idea of seismicity in the UAE could be determined through the global seismic data in the gulf region as shown in the following figure $1.1[6]$.

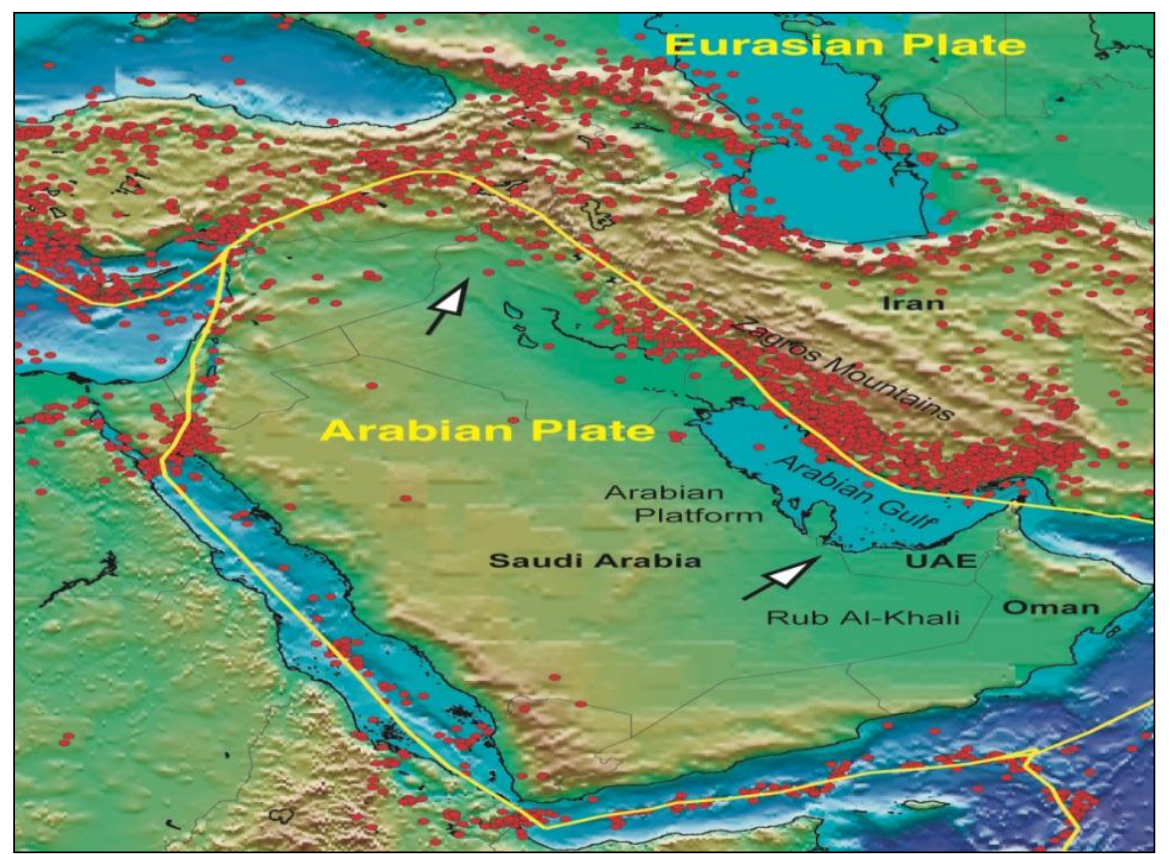

Figure 1.1: Regional map of earthquakes in red circles and seismic activity along the Zagros Mountains near the UAE “[6]”.

In regard to seismic issues in the UAE one published report produced by Kazmi which indicated that "a large portion of the UAE is outside the active seismic area but some parts of the northern emirates are located within technically active areas. The northern emirates are situated on a body of continental rock that forms the Arabian Platform [7].

\subsection{Dust \& sand storms in the UAE}

Estimates have been made that annually up to about two billion tons of dust are carried up into the atmosphere, mainly by dust storms [14]. One dust storm can lift and deposit more than 200 tons of dust [14]. The Arabian Peninsula has been listed as one of five major dust-producing regions. The statistical study conducted by Mr. De Villiers from Weather Services International in Birmingham UK indicates that frequent dust \& sand storms strike the UAE according to the following table 1.1:

\begin{tabular}{|c|c|c|c|}
\hline Year & Dust events & Dust storms & Total \\
\hline 1994 & 10 & 5 & 15 \\
\hline 1995 & 16 & 2 & 18 \\
\hline 1996 & 13 & 1 & 14 \\
\hline 1997 & 10 & 2 & 12 \\
\hline 1998 & 12 & 2 & 14 \\
\hline 1999 & 18 & 7 & 25 \\
\hline 2000 & 15 & 3 & 18 \\
\hline 2001 & 10 & 0 & 10 \\
\hline 2002 & 17 & 2 & 19 \\
\hline 2003 & 20 & 8 & 28 \\
\hline Total & 141 & 32 & 173 \\
\hline
\end{tabular}

\subsection{Flooding hazard in the UAE}

The UAE climate is characterized by high temperatures, humidity and low precipitation levels. The UN Food and Agriculture Organization (FAO) have reported that the UAE's long term average precipitation rates are around $78 \mathrm{~mm}$ 
per year. The World Health Organization produced a flood hazard distribution map in the UAE as showing in the following figure 1.2:

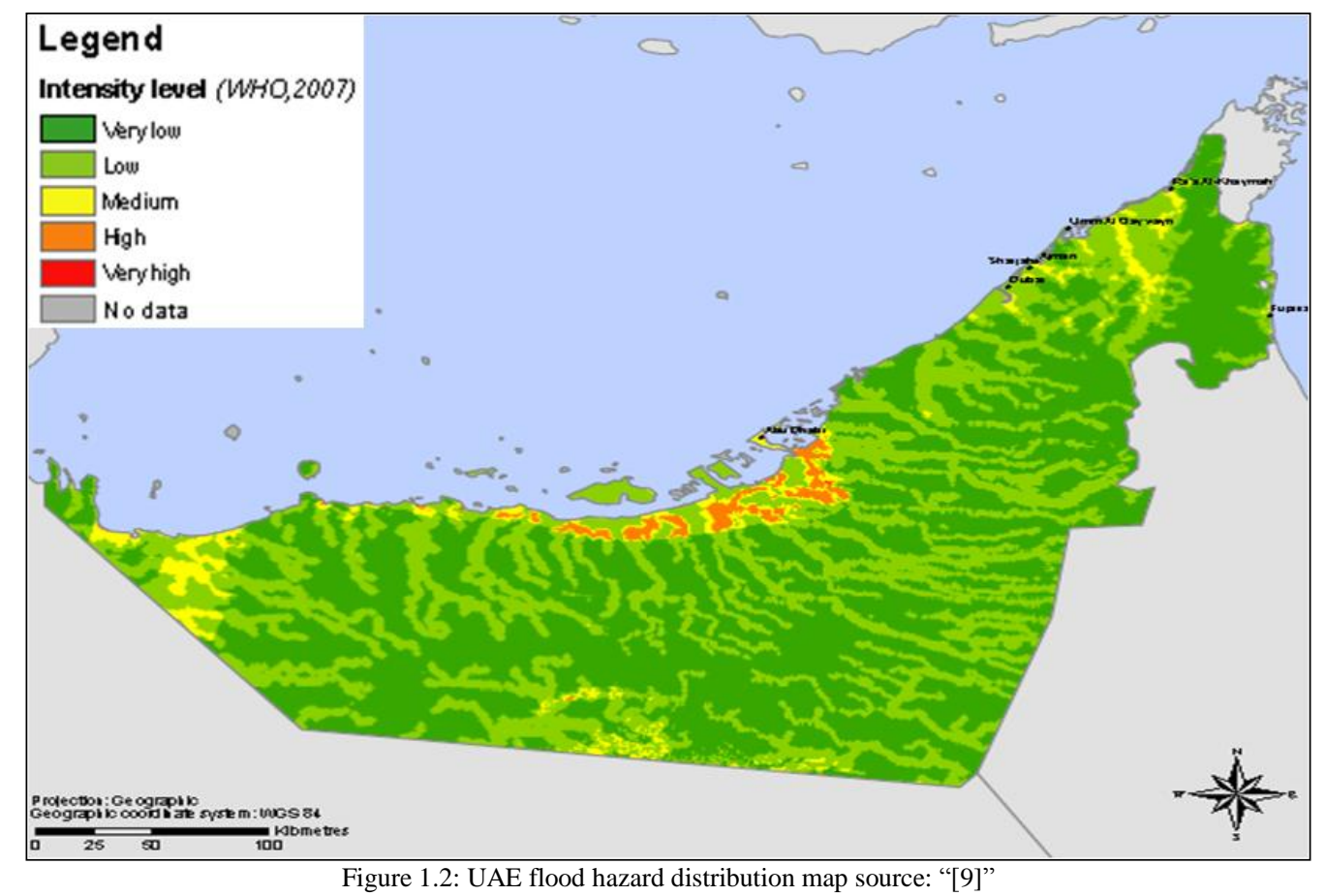

The UAE has its own unique climate and weather condition. Since it is a newly established country there is an obvious lack of historical data recorded over a long period of time.

\section{Methodology \& data collection}

Detailed In data collection phase, two types of data were acquired, primary and secondary data set. Supporting the risk assessment accuracy requires reliable sources especially the ones produced officially by government. The secondary data set was based on the relative scientific studies. The information has been used to support the logic of the method utilized in assessing the natural hazards in the UAE.

The UAE is potentially exposed combination of natural hazards with different severity and frequencies specifically discussed topic in this paper, namely, earthquakes, tsunami, dust storms, sand storms, climate change and flooding. These hazards are usually assessed individually and sometimes assessed together as they may occur in combination at the same time. The main method implemented in assessing the natural hazards is the risk matrix which is "The level of risk associated with a particular issue. They do this by categorising the likelihood of harm and the potential severity of the harm. This is then plotted in a matrix [2]. Within this study, the risk matrix based approach is applied on a regional scale.

The following formula is used to calculate the risk level:

Risk $=$ consequence $\mathrm{x}$ likelihood

Results are presented as hazard maps and conceptual discussion based on applicability, regions of are divided according to their exposure of risk level. Hazard maps presented as single hazard and multi-hazard that combines overall hazards. There is a specific input for each hazard map:

\section{1) Seismic Activity:}

Seismic vulnerability mapping carried out by historical data analysis and scientific research that was conducted. The map reflects the following columns:

Severity category: Serious

Probability of Occurrence: Likely 475 Yr.

As shown in the following figure 1.10:

The map provides sufficient level of information using the indicated parameter presented by the return period of 475 yrs and $0.34-.65 \mathrm{~g}$. 


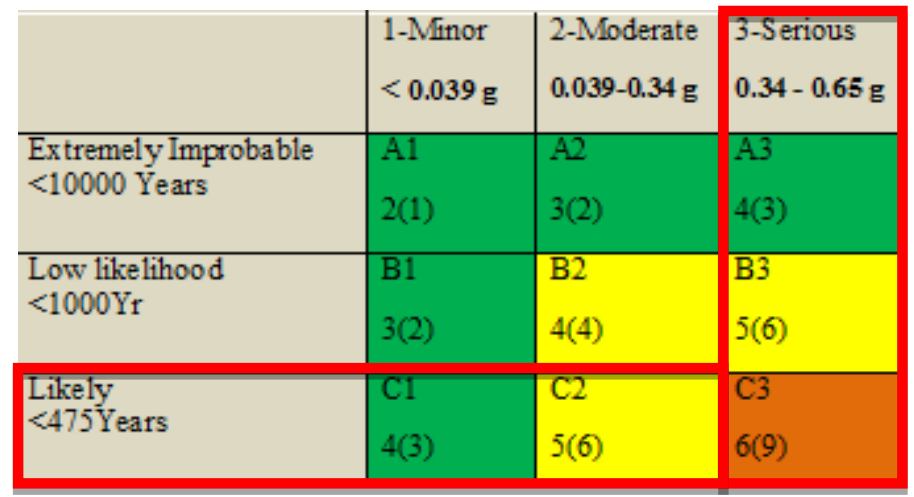

Figure 1.10: Risk columns used in seismic hazard map

\section{2) Tsunami:}

The method used in tsunami analysis involves the historical data according to the sources of risk which mainly comes from Indian Ocean. The map reflects the following columns:

Severity category: Serious

Probability of Occurrence: Likely 475 Yr.

As shown in the following figure 1.11:

\begin{tabular}{|l|l|l|l|} 
& $\begin{array}{l}\text { 1-Minor } \\
\mathbf{1 - 2} \mathbf{~ m}\end{array}$ & $\begin{array}{l}\text { 2-Moderate } \\
\mathbf{2 - 3} \mathbf{~ m}\end{array}$ & $\begin{array}{l}\text { 3-Serious } \\
\mathbf{4 - 6} \mathbf{~ m}\end{array}$ \\
\hline $\begin{array}{l}\text { Extremely Improbable } \\
<3000 \text { Years }\end{array}$ & A1 & A2 & A3 \\
$4(1)$ & $3(2)$ & $4(3)$ \\
\hline $\begin{array}{l}\text { Low likelihood } \\
<1000 Y r\end{array}$ & B1 & B2 & B3 \\
\hline $\begin{array}{l}\text { Likely } \\
<500 \text { Years }\end{array}$ & $3(2)$ & $4(4)$ & $5(6)$ \\
\hline
\end{tabular}

Figure 1.11: Risk columns used in tsunami hazard map

\section{3) Flood:}

Flood hazard map was generated based on the risk matrix developed for this type of hazard; the map only reflects the following columns:

Severity Category: Moderates

Probability of Occurrence: Occasional

As shown in the following figure 1.12:

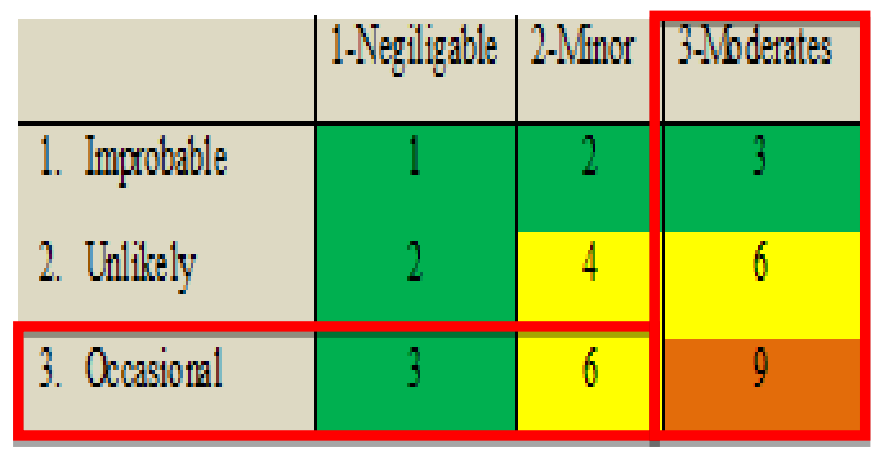

Figure 1.1: Risk columns used in flooding hazard map

This provides a reasonable flood hazard mapping for the UAE, the average risk level is more applicable for the UAE nature since the flooding hazards is not severe as compared to other parts of the world. 


\section{4) Dust \& sand storms DSS:}

The assessment for DSS is done differently. This is because these events happen very often and strike regionally. The conceptual risk assessment was done discussing the historical data, literature review and risk analysis. The hazard map was made based on the historical data and the direction of the winds based on their risk level.

\section{5) Climate change:}

The assessment for climate change has included the latest studies and investigations conducted globally and for UAE. The only related aspect of climate change is the rising of the sea level. Since the coastal flooding is discussed in tsunami section, the climate change analysis result was merged under tsunami result and discussion.

\section{6) Multi hazard:}

The final product in the results chapter is the multi hazard map which combines all hazards, overlying all maps produced and judging the location of higher risk level area. Multi hazard map shows the logical outputs of risk assessment. Treating combinations of hazards requires using a logical implementation of the information obtained from the risk analysis of each hazard. All hazard maps produced were overlaid over each other to show the higher risk areas versus lower risk areas.

\section{Data evaluation \& analysis}

\subsection{Overview of UAE geological setting}

In this study the geological information is vital to be included as the analysis heavily depends on understanding the geological and geographical setting of the UAE. The Arabian plate, which the UAE is located on, is moving in a NorthEastward direction, away from the spreading centre that runs the length of the seafloor beneath the Red Sea, to where it is sub-ducting underneath the Iran plate.

The natural hazards are interpreted through the historical events and the potential of such events to be occurred due to the regional geography and geology. The UAE consists of different geographical features including land and water as the country is located at the Arabian Gulf and Gulf of Oman on the Eastern side. Mainly the coastal area of the capital, Abu Dhabi has the salt encrusted flat, which is known as coastal "Sabkhas". Extensive areas are covered by sand dunes. The major surface geology is buried under a cover of sands which form high dune reaching heights of about $150 \mathrm{~m}$ inland. The north east area of UAE consists of high mountains as the Oman Mountains form part of the region. The Western part of the UAE consists of flat areas covered by loose of sediments and sands, firm ground is found about 50 metres deep. The North bordering country of Iran has a geological active mountain region called the Zagros Belt that is located in the Southern part of the country. Oman Mountains cover the northern most region of UAE providing an excellent transition medium for seismic waves to travel.

Typically there is a lack of fresh underground water in the UAE. The saline water invades all of the coastal aquifers. There are two separate regional aquifer systems, the North Eastern Area and Western Area. In fact, the reason for the two divisions of the hydro-geologic systems is due to the differences in the geological structures. The following figure 1.13 shows the geographical location of the UAE.

Regionally, the South Eastern part of UAE boarder is the Rub al-Khali (The Empty Quarter) desert which is the main source for dust and sand that contributes to the dust storms in the UAE. Across the Arabian Gulf, the Zagros Mountains are located in Southern Part of Iran. This mountain series is tectonically active which frequently experience some seismic activity "[31]"

\subsection{UAE seismic activity}

Recent studies have shown that there is potential for seismic activity in the UAE caused by Zagros Mountains which pose a threat to safety of people [6]. The destructive impacts from earthquakes can be mitigated by understanding the sources and areas which are more likely to be impacted.

An evidence for seismic activity was recorded near Masafi which is located in the North Eastern part of the UAE on March 2002 with a magnitude of 5.1 Richter scale and was detected and located by global seismic networks. The epicentre of the earthquake was located at $20 \mathrm{~km} \mathrm{NW}$ of Fujairah city [6].

Unfortunately, the UAE has poor historical data in term of seismic records; the importance of historical data is manifested through the probability of occurrence to enhance the accuracy of the risk matrix results.

Through the discussion above, the North Eastern region of the UAE was more highlighted to be a potential for seismic activity while the rest of the areas of the UAE are relatively safer. This is because the topography in the Central and Western part of the UAE is characterized by gravel and sandy layers. The compaction of the ground is relatively low 
compared to the solid ground in the north eastern part, so the conductivity of the seismic waves travels in more velocity through the solid rocks i.e. mountains than the gravels and sands. So the seismic intensity is limited by the geological formation and can be enhanced through the solid rock.

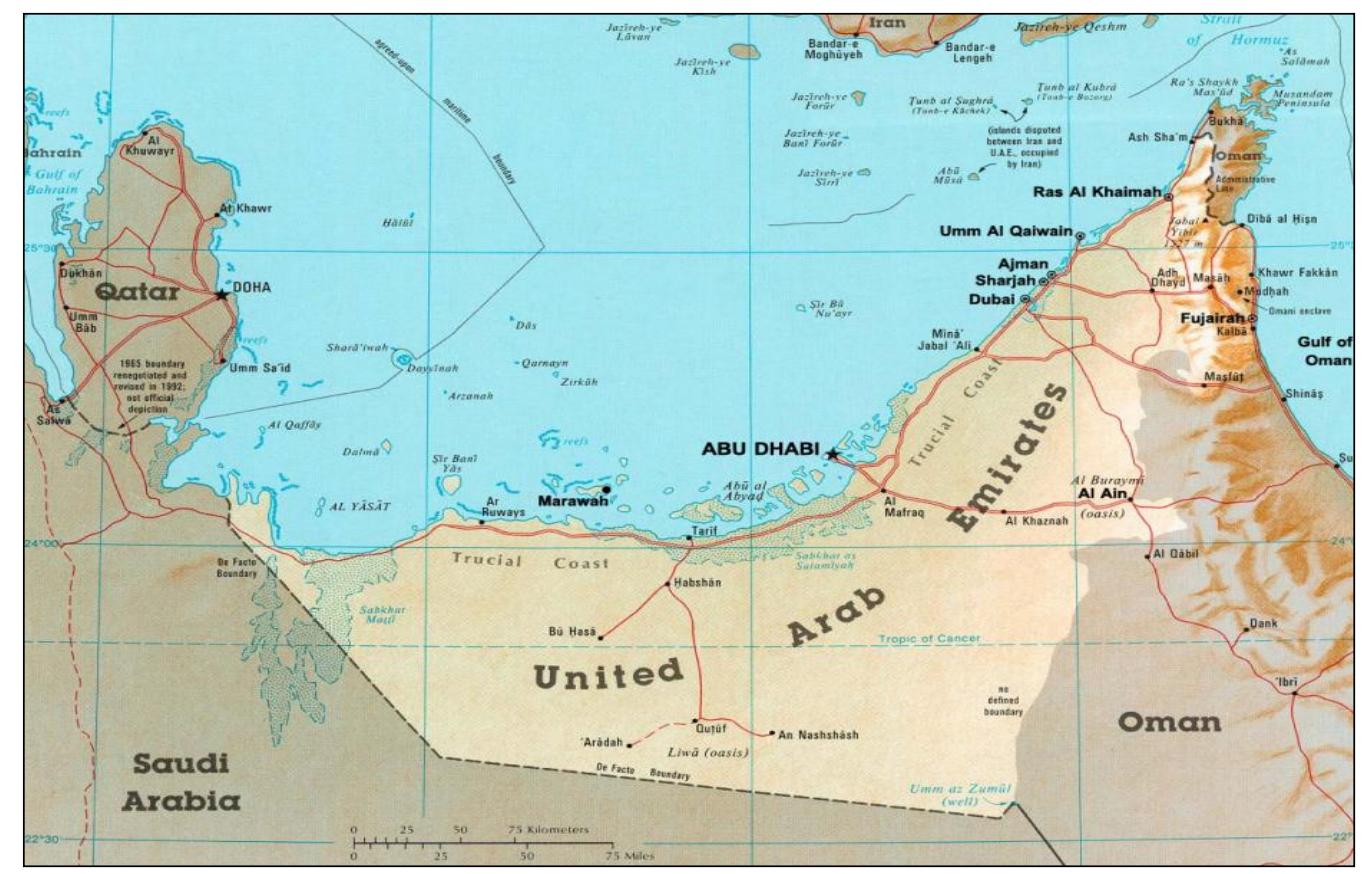

Figure 1. 2: UAE location Map Source: “[36]”

\subsection{Climate change \& flooding in the UAE}

The first step of determining candidate area witnesses the applicant using topographic maps to speculate areas with fewer hazards. The most suitable location would avoid major flood-prone area. The UAE is classified as an arid subtropical desert with about $70 \%$ of rain takes place in the winter season period of December to mid-March. The mean annual temperature in the UAE is $28{ }^{\circ} \mathrm{C}$ and can exceed $49{ }^{\circ} \mathrm{C}$ during summer. Flooding in the UAE is rare since the precipitation rate is very low in average of $78 \mathrm{~mm}$ per year and evaporation rate is about 2 metres per year. Desert areas are known for flash flooding; the floods typically occur in the Eastern region, in association with strong rain storms "[24]". The low porosity and permeability of the existing igneous in the eastern region enable the rainwater to flood over the surface for short period of time. The Western region is mainly dry and lacks surface flood, because of high porosity and permeability of sands.

The only permanent surface water is the sea and other seasonal surface water as a result of rain called "wadies". The "wadies" can last for 2 or 3 weeks as maximum with high intensity but they are a common occurrence in mountain areas because of the elevation differences, slopes, trenches and water pathways. In some unusual cases, there is a possibility of having wadies in the desert area but rapidly dry once the rain stops. This means that any rainfall or flood water occurring in the sandy areas is rapidly evaporated or soaks into sand "[32]"

Another potential flooding source is the groundwater. In general the water table in the UAE is fast depleting because of long-lasting draught conditions. The recharge rate is much lower than the discharge so it is unlikely to get such type of flooding. Close to the shorelines there are some broad areas of super tidal salt flat called "Sabkhas" of depth varying from 1 to 1.5 metres the evaporation is very intensive and the salinity is high. Sabkhas only exist within flat low areas where the west side of the UAE is considered perfect environment rather than the high areas with complex topography. Sabkhas issues may include strength surface subsidence during the dissolution of salts, corrosive caused by salinity of the ground. Therefore, Sabkhas area must be examined before planning a development. In general, the issues of groundwater and Sabkhas are more or less likely to pose high risk of flooding due to their characteristics in the region and climate condition in the country.

Climate change has become a global issue. Lately large areas of the world have been affected directly by this phenomenon. In the UAE long term variations in temperature and precipitation could create adverse impacts especially in sea level rising. Regardless of what level of global warming is already occurring, it will result in an unavoidable increase in sea levels.

Globally, scientists have predicted an increase of 5.8 degree Celsius after approximately 80 years. This prediction is a result of the blanket of carbon dioxide growing thicker due to greenhouse gas emissions. Dr. Keith from British Safety 
Council has stated that "The Stockholm Environmental Institute has carried out some climate change modelling of predicated sea level rises in the UAE and I used a series of model graphics to show how Abu Dhabi and Dubai would be under water by 2100 [12].

\subsection{Tsunami risk in UAE}

The UAE has about $1318 \mathrm{Km}$ of coastline along the Arabian Gulf and Gulf of Oman. Tsunamis are generated when the water column is physically moved such disturbance is usually formed because of earthquakes, huge landslides and volcanic eruptions [33]. The largest source for tsunami comes from the Eastern hemisphere "Indian Ocean" in particular where it is believed that large size of the Indonesian tsunami was not only due to the magnitude of the earthquake but also because the seafloor displacement in deep ocean [33].

Gathering evidences is the most significant tool to determine the level of risk and the likelihood of tsunami occurring in the UAE. Historical records for tsunamis were made by UAE University showing events mainly occurred in Indian Ocean, Indonesia, Pakistan and Iran. A total of 8 events were retrieved from the history between the years of (324 B.C2004 A.D) [18]. Most of these tsunami events were due to large magnitude of earthquakes and one event due to volcano eruption. The records indicated that the UAE had no great impact of tsunami but only on the eastern that is located on the coast of Gulf of Oman had very minor impact. Even the deflected waves from Indian Ocean would lose energy once the waves travelled to the Arabian Ocean [18]. Most of the earthquakes occur regionally close to the UAE take place inland and away from the coasts which somehow decrease the influence of seismicity on the coast. The average water depth in Arabian Gulf is 36 metres while the Indian Ocean depth is 3890 metres, the huge difference of depth explains the theory that tsunami is unlikely to occur in the Arabian Gulf [19]. Despite the fact that the Gulf is shallow; it does not have coastlines prone to landslides and volcanoes so the probability of occurrence for tsunamis is low.

\subsection{Dust and sand storms (DSS)}

Middle East is a famous for frequent DSS. To some extent it has become a usual event. DSS are a natural phenomenon and cannot be all controlled or eliminated, typically they are caused by drought, land desertification and overgrazing. Scientifically, there should be certain conditions associated together in order for such event to occur; the intense heat of the ground creates convection currents. As a consequence, a strong wind is formed with high momentum that is able to drive the sand particles away travelling in high velocity in great distances. During periods of clear skies and light winds, the land surface is heated and localized pockets of air start to rise. Usually during the winter season where the rainfalls take place the chances of having DSS is lower than the rest of the year but even in the wet season the likelihood of DSS to occur is still possible. The primary source sand storm in the UAE, the Empty Quarter "Rub' al Khali" (Saudi Arabia) which is one of the largest sand deserts in the world and the secondary source for dust is Iraq and Iran. The UAE is exposed to frequent DSS as the location, heat and dunes trigger the storms to occur very often

Although dust storms and sand storms have been discussed together as one character, slight differences exist between them.

\section{Sandstorm:}

Sandstorm with dust generated by local high winds and characterized by the presence of both sand and dust particles (heavy sand particles at a low altitude and dust in a potentially very high cloud) and a limited duration (less than a day)

\section{Dust phenomenon:}

Driven from distant regions by more or less high winds, not necessary correlated with high winds at the site, and characterized by the presence of dust particles and a duration that might be long

Typical sand storms reach heights of up to just $15 \mathrm{~m}$, contain sand particles with average sizes between 0.15 and 0.30 $\mathrm{mm}$, have wind speeds exceeding $4.5 \mathrm{~m} / \mathrm{s}$, and last as long as wind speeds continue. Unlike a sand storm, the average height of a dust storm is in the range of 900 to $1,800 \mathrm{~m}$, and stronger storms contain dust to heights of 2,400 to $3,000 \mathrm{~m}$. In extreme storms, haze and dust have been documented as high as $12,000 \mathrm{~m}$. "[34]". The following sat image figure 1.14 shows how the UAE gets affected by sand storms.

The determination of DSS intensity is by the restrictions on visibility combined with the speed of wind. For instance, a study was conducted in Kuwait to measure the intensity of sand storms found that when winds were in excess of $9.5 \mathrm{~m} / \mathrm{s}$ and visibility was less than $1,000 \mathrm{~m}$ and when visibility was reduced to less than 200 metres, a severe sand storm or dust storm was reported. Generally DSS impact the climatology in every region of the UAE and there is no region classified to be safer from such extreme condition. 


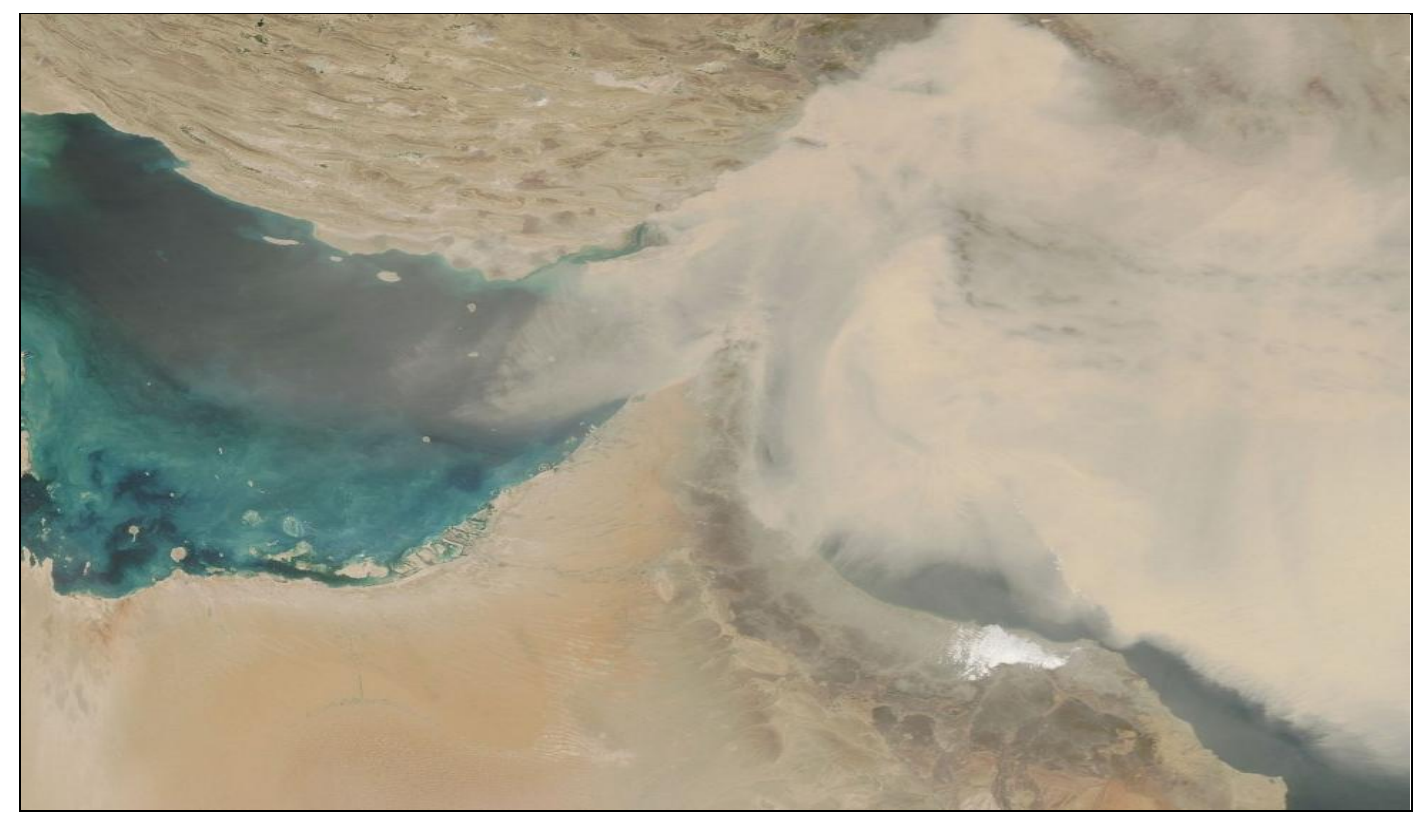

Figure 1.3: DSS sat image of UAE. Source: “[35]"

\section{Risk assessment}

1) North Eastern Region: It is considered to be the highest risk region, since the seismic activity is higher and possibility of tsunami is greater. Also surface flooding is greater comparing to other areas.

2) Central Region: It has a less risk since seismic activity is relatively low and tsunami possibility is lower but its underground rock formation has high seismic wave conductivity. The surface flooding is less but greater chance of having overflow from the mountain areas in the north

3) Western Region: It is the safest region according since seismic activity is so low and tsunami possibility of occurrence is low. The underground formation is loss consisting of gravels and unconsolidated materials which have poor physical properties in terms of seismic wave conductivity. The surface water flooding is rare since it's surrounded with deserts.

\subsection{Natural hazards risk assessment}

Risk assessment is process which involves evaluating the significance of a hazard and its consequences, either quantitatively or qualitatively. This process is used by industries which deal with hazards. Even when hazards have been identified, there are uncertainties associated with these hazards. A risk matrix is related to two different dimensions probability of occurrence and severity. The matrix is used as evaluation tool when several hazards have been identified to assist comparing the different risks. Risk matrices are also utilized in helping to define risks that need further considerations. Once risk matrices are constructed, the required hazard maps can be generated which portray levels of possibility of hazard occurring across geographical region. The overall impacts of natural hazards in the UAE have been recognized and investigated as initial step to produce the risk assessment. The relative risk identification for the UAE was either based on quantitative historical and statistical or engineering judgment. Ideally hazard identification should include all possible hazards but in this research it will be only limited to the highlighted hazards.

Generally there are two types of natural risk assessments; the first one is single-risk assessments which associated on assessing a single risk from one particular hazard i.e. seismic occurring on specific geographical region. The second type is multi-risk assessments that contain several hazards on a particular geographical region [15]. This study will be using both assessing individual hazards and at the end producing a multi hazards map.

In the UAE natural hazards occur in different intensities that are subjected into variety of conditions, the level of impact may differ from location to another. For example, the level of impacts of earthquakes occurring in west side of the US is greater than the east side. Risk scenarios are believed to predict of how likely such risk may develop in future. Typically the scenario is mostly based on experiences from the past, but also events that may have impacts and have not occurred so far should be considered i.e. climate change.

There are two main dimensions of risk matrix the probability and severity. Probability is a mathematical examination of results based on experience, observation, history and predication. Severity will involve the impact and consequences of the event; this usually is characterized by the magnitude of the event. 
For risk assessments it is a primary issue where scenarios are often chosen, as this will validate the reliability of risk assessment, this is compared to the global situations of risks and their varying degrees of intensities that are indeed possible in reality [15].

The framework of the risk assessment will be built systematically; therefore the obtained results will be represented in a hazard map. Each hazard will be assessed individually and at the end an overall hazard map will be produced for regional representation of hazard level in the UAE. The international considerations of the natural hazards which were discussed earlier will be included as benchmark for some of the assessments.

\subsection{Seismic risk assessment}

Assessing the seismic risk using a matrix will provide the severity and the consequences. In such case, two methods can be selected either quantitative or qualitative. PGA is complex to measure unlike the magnitude; the PGA "is a maximum acceleration experienced by a particle during a course of earthquake motion" the movement of the particle can be described as its changing position as a function of time "[1]". The ground acceleration will decrease as the distance from the epicentre increases; therefore time and distance are major factors in measuring the PGA.

Generally in seismic hazards studies the assumed rate and magnitude distribution are similar to the ones which have occurred in the past.

Seismic severity of consequences:

The severity of consequences is based on the effects of ground vibration. The intensity varies based on the magnitude of the ground shaking. The severity is associated with energy released from the epicentre of the earthquake. Typically earthquakes cause more damage when their epicentres get closer to the surface as the PGA values increase dramatically. The following table 1.3 represents the perceived values and their potential damage around the world.

Table 1. 1: Description of seismic severity in PGA values. Source "[10]"

\begin{tabular}{ccc}
\hline Peak Ground Acceleration PGA $(\mathrm{g})$ & Perceived Shaking & Potential Damage \\
\hline$<0.0017$ & Not Felt & None \\
$0.0017-0.014$ & Weak & None \\
$0.014-0.039$ & Light & None \\
$0.039-0.092$ & Moderate & Very light \\
$0.092-0.18$ & Strong & Light \\
$0.18-0.34$ & Very Strong & Moderate \\
$0.34-0.65$ & Severe & Moderate to Heavy \\
$0.65-1.24$ & Violent & Heavy \\
$>1.24$ & Extreme & Very Heavy \\
\hline
\end{tabular}

Table 1.2: severity consequences of earthquake. Note the values have been modified from the original source. "[11]"

\begin{tabular}{|c|c|}
\hline & 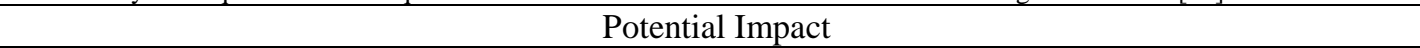 \\
\hline Light & 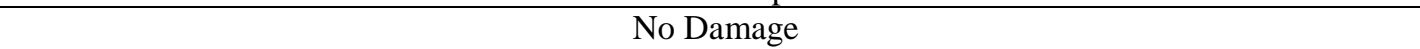 \\
\hline$<0.039 \mathrm{~g}$ & $\begin{array}{c}\text { This event is categorized as minor earthquake, this type of seismic activity usually occurs in great } \\
\text { depth in the geological formation. It is either not felt only recorded by local detector stations or it is } \\
\text { possible to have a moderate perceived shaking. }\end{array}$ \\
\hline Moderate & Moderate impact \\
\hline $0.039-0.34 \mathrm{~g}$ & $\begin{array}{l}\text { Seismic activity occurs within this range can have light to very strong perceived shaking. It can cause } \\
\text { very light to moderate damage to buildings and basement i.e. wall cracks. }\end{array}$ \\
\hline Serious & Serious damage \\
\hline $0.34-0.65 \mathrm{~g}$ & $\begin{array}{l}\text { To buildings, structures and installations. Seismic activity within this range is classified to be serious, } \\
\text { the impact ranges between moderate to heavy. }\end{array}$ \\
\hline Critical & Fatal Injuries \\
\hline $0.65-1.24 \mathrm{~g}$ & Seismic activities within this range have more tendencies to cause fatalities. \\
\hline Catastrophic & Massive damage to the facilities and surroundings. \\
\hline$>1.24 \mathrm{~g}$ & This type of earthquake is able to cause massive damage. \\
\hline
\end{tabular}

Seismic probability of occurrences: 
According to the Health Safety Executive HSE the quantitative regional seismic hazard assessment is computed as following 100 years; 200 years; 475 years; 1000 years and 10,000 years. These annual probabilities correspond the return periods which are widely used in the risk assessment. The same probability values will be used when evaluating the risk matrix. The rest of the probability values will be tailored in a form of risk matrix associated with the available previous UAE seismic studies.

Table 1.3: Seismic probabilities of occurrences

\begin{tabular}{|c|c|}
\hline & Description \\
\hline Extremely Improbable & Practically Impossible \\
\hline$<10000$ Years & It means it is never been recorded. \\
\hline Low likelihood & Very low chance of occurrence \\
\hline$<1000$ Years & $\begin{array}{l}1000 \text { years gives a low likelihood of that an event can occur in this time frame. } \\
\text { In case of seismic activity, if there is an evidence of seismic occurrence. }\end{array}$ \\
\hline Likely & Possible of occurring sometime \\
\hline$<475$ Years & $\begin{array}{c}\text { Every } 475 \text { years seismic activity, this period can be critical once evidence } \\
\text { shows that it has happened around this period. }\end{array}$ \\
\hline Highly Likely & Some seismic activity has been recorded \\
\hline$<200$ Years & Seismic activity has been recorded within this range of time. \\
\hline Near Certainty & Possibility of repeated seismic activity \\
\hline$<100$ Years & $\begin{array}{l}\text { Repeated earthquakes takes place once every } 100 \text {. This is considered to be an } \\
\text { active seismic area. }\end{array}$ \\
\hline
\end{tabular}

\section{Seismic risk matrix:}

Table 1.4: $5 \times 5$ Risk matrix for seismic assessment

\begin{tabular}{|c|c|c|c|c|c|}
\hline Probability of Occurrence & \multicolumn{5}{|c|}{ Severity Categories } \\
\hline & $1-$ & $2-$ & $3-$ & 4- & $5-$ \\
\hline & Minor & Moderate & Serious & Critical & Catastrophic \\
\hline & $<0.039$ & $0.039-0.34$ & $0.34-$ & $0.65-$ & $>1.24 \mathrm{~g}$ \\
\hline & g & g & $0.65 \mathrm{~g}$ & $1.24 \mathrm{~g}$ & \\
\hline A. Extremely & A1 & A 2 & A3 & A4 & A5 \\
\hline Improbable & $2(1)$ & $3(2)$ & $4(3)$ & $5(4)$ & $6(5)$ \\
\hline$<10000$ Years & & & & & \\
\hline B. Low likelihood & B1 & B2 & B3 & B4 & B5 \\
\hline$<1000 \mathrm{Yr}$ & $3(2)$ & $4(4)$ & $5(6)$ & $6(8)$ & $7(10)$ \\
\hline C. Likely & $\mathrm{C} 1$ & $\mathrm{C} 2$ & $\mathrm{C} 3$ & $\mathrm{C} 4$ & $\mathrm{C} 5 \mathrm{C}$ \\
\hline$<475$ Years & $4(3)$ & $5(6)$ & $6(9)$ & $7(12)$ & $8(15)$ \\
\hline \multirow{2}{*}{$\begin{array}{l}\text { D. Highly Likely } \\
<200 \text { Years }\end{array}$} & D1 & D2 & D3 & D4 & D5 \\
\hline & $5(4)$ & $6(8)$ & $7(12)$ & $8(16)$ & $9(20)$ \\
\hline E. Near Certainty & E1 & E2 & E3 & E4 & E5 \\
\hline$<100$ Years & $6(5)$ & $7(10)$ & $8(15)$ & $9(20)$ & $10(25)$ \\
\hline
\end{tabular}

Table 1.5: Interpretation of seismic hazard risk levels

\begin{tabular}{cc}
\hline Risk Category & Level of Risk and Measures \\
\hline $1-3$ & The risk posed by the seismic hazard is ranked to be acceptable. There is no harm expected. \\
According to PGA values. & This category is ranked as being acceptable. \\
$4-8$ & The risks posed by seismic hazard within this ranking consider being unacceptable. \\
$12<$ & Usually risk within this category represents high hazardous area. The risks posed by seismic hazard \\
are great.
\end{tabular}

The seismic matrix has determined the intensity of seismic hazard in a form of interaction between severity and probabilistic scheme. The methodology presents a seismic risk description having a various potential consequences. Seismic risk matrix analysis was conducted using the matrix $5 \times 5$ which is the typical approach to assess the vulnerabilities of locations. Optimum seismic analysis for UAE can be well addressed by assessing the consequences and probabilities as extremely improbable, low likelihood, likely, high likely or near certainty. Lower frequency values 
were assigned to events which are improbable to occur and the frequency increases gradually to the level of near certainty. Results reveal a logical way of assessing the seismic hazard; the outputs obtained were based on the data gathered and the international considerations of seismic hazard which enhances the reliability of the product.

\subsection{Flooding risk assessment}

Flood risk assessment aims to help concentrate the efforts on areas vulnerable to flooding; this significant issue poses a potential physical damage. The severity and the probability of occurrence vary from place to another and this allows flooding risk assessment to indicate the areas susceptible to flooding.

Typically flooding risk assessment takes into account the probability of occurrence and their physical characteristics (e.g. flow velocity, flood depth and duration) [16]. The risk assessment for flooding potential in the UAE will be carried using the qualitative approach; the results will be expressed in qualitative descriptions of risk. The main reason of choosing the qualitative method is because the flooding hazard cannot be quantified due to lack of historical information. Therefore the magnitude and probability of occurrence are not available to support the quantitative analysis. The absence of permanent fresh surface water i.e. lakes, rivers provide scarce potential flooding chances due to low rainfall, high temperatures and extremely high evaporation rates.

\section{Flooding severity of consequences:}

The assessment will cover flooding from wadies, Sabkhas and surface flood as result of rainfall. The likelihood of flooding is heavily depends on precipitation rate and the estimated impact on areas. This will combine the understanding of where flooding is likely to occur and its severity.

\section{Flooding probability of occurrences:}

It is hard to characterize the probability of flooding hazard because of the uncertainty associated with predicting the occurrence of flooding. One of the optimum ways is to apply an approach that uses a combination of international ways of dealing with probability of flooding with the UAE flooding condition. In the UK, for example, the probability is measured using data set established through years of records using gauges but it is possible to use a conceptualized flood risk probability to deal with the uncertainty [21]. The uncertainty level associated with probability estimation is more in UAE; some traces of historical events recorded might help to reduce uncertainties in the estimation.

The main considerations of probability risk criteria will examine the possibility of flooding occurrence due to heavy rainfall, wadies and Sabkhas in regard of the geographical location.

Table 1.6: Severity of consequences for flooding

\begin{tabular}{|c|c|}
\hline Severity of consequence & Characteristic \\
\hline Insignificant & No Significant risk posed. \\
\hline Minor & Slight risk of minor flooding to occur, it can be ranked as usual as result of heavy rain. \\
\hline Moderate & Moderate risk requiring additional controls and measures water level is relatively high. \\
\hline Critical & High potential of flooding, water level is high enough to overwhelm facilities. \\
\hline Catastrophic & Massive flooding. \\
\hline & Table 1.7: Flooding probabilities of occurrences \\
\hline Probability of Occurrence & Characteristic \\
\hline 1-Improbable & Hazards are unlikely due to topography and climatology. \\
\hline 2-Unlikely & Hazards are possible but unlikely to occur. \\
\hline 3-Occasional & Hazards are likely to occur in longer periods i.e. 25 years. \\
\hline 4-Highly Likely & Hazards are likely to occur from time to time i.e. 5 years. \\
\hline 5-Frequent & Hazards are likely to occur in shorter time. \\
\hline
\end{tabular}

Flood risk matrix:

\begin{tabular}{cccccc}
\hline \multicolumn{7}{c}{ Table 1.8: Flooding Risk Matrix } \\
\hline Probability of ccurrence & \multicolumn{5}{c}{ Severity Categories } \\
\hline Improbable & 1- Insignificant & 2- Minor & 3-Moderates & 4-Critical & 5-Catastrophic \\
Unlikely & 1 & 2 & 3 & 4 & 5 \\
Occasional & 2 & 4 & 6 & 8 & 10 \\
Highly Likely & 3 & 6 & 9 & 12 & 15 \\
Frequent & 4 & 8 & 12 & 16 & 20 \\
\hline
\end{tabular}


Table 1.9: Interpretation of flood hazard risk level

\begin{tabular}{cc}
\hline Risk Category & Level of Risk and Measures \\
\hline $1-3$ & Green considers being low risk with low frequency. \\
$4-8$ & Yellow is minor risk. \\
$9-12$ & The risks within this range considerably high. \\
$12<$ & Generally risks within this range are too high. \\
\hline
\end{tabular}

The risk matrix is practically applied to demonstrate the risk levels from low to high based on the evaluation of flood hazards and vulnerabilities. The risk matrix represents the level of risk; each cell expresses a risk score which is determined by multiplying up the severity damage and probability of flood hazard. Using the matrix shown, the risk cells are expressed by colours and values that are used to help identify sites that are safe from flooding hazard. The higher the value the higher the risk is imposed in that area, the estimated risk is classified in four categories. Extreme risk scores are not directly applicable to UAE; they are more related to existed severe cases around the global, using these extreme values are helpful to determine the risk level in regard of real situations in other parts of the world.

The information helps of clarifying areas susceptible to flood risk; the reason of selecting small time scales into probability scale is because of recent cyclones that struck the nearby country of Oman. This can potentially affect UAE by the heavy rains as a result of recent cyclones (please refer to climate change section for further information).

\subsection{Tsunami risk assessment}

Since there are no general guidelines used that state how to estimate tsunami risk, the appropriate risk assessment will be using the risk matrix to determine the risk level based on probability and severity. Tsunami, like other natural hazards, poses a great physical threat to any critical development. The study of tsunami phenomena has always received less attention; this is probably because of the difficulties and uncertainties related to the availability of data. In general large tsunamis are likely to occur much less frequently than for floods, landslides or earthquakes. Usually tsunamis take place in seismically active regions but in fact there are several other trigger conditions i.e. landslides. The tsunami risk assessment applied to the UAE is based on a general historical data that was captured; this will help to produce tsunami risk regional map. Here is a summary that will used to help constructing a risk matrix in assessing tsunami hazard,

1) The North Eastern side of the Arabian Gulf is a tectonically active region [18].

2) It takes a strong earthquake (> $7.0 \mathrm{M})$ to generate a tsunami, because the tsunami energy is dependent on the magnitude of the earthquake [15].

3) The Arabian Gulf is a shallow sea with a maximum depth of only $60 \mathrm{~m} \mathrm{[18]} \mathrm{and} \mathrm{average} \mathrm{water} \mathrm{depth} \mathrm{of} \mathrm{about}$ $36 \mathrm{~m}$ "[19]". Tsunamis are considered destructive when they are generated in deep oceans (water depth of more than $1,000 \mathrm{~m})$ as waves can carry a tremendous amount of energy.

The assessment for tsunami will be carried out using a combination of quantitive and qualitative method. The available data and resources support developing the combined analysis to produce the output of the assessment in a form of risk matrix.

Tsunami severity of consequences:

To determine the severity of consequences the best approach is to take example from previous study. The severity levels demonstrate the impact of tsunami based on the waves generated and the source of occurrence. The following table illustrates the possible impacts of tsunami:

Table 1.10: Tsunami severity of consequences. Source: [37]

\begin{tabular}{ccc}
\hline Severity of Consequence & Maximum Wave Height (Metres) & Description of Damage \\
\hline Insignificant & 1 to 2 & No damage \\
Minor & 2 to 3 & Houses and small construction units are flooded \\
Moderate & 4 to 6 & Timber houses and earthen buildings are damaged \\
Critical & 10 to 20 & Timber buildings, vessels and people are swept away \\
Catastrophic & More than 30 & Serious damage along more than 500 km of coast \\
\hline
\end{tabular}

The above table 1.12 demonstrates consequences based on maximum wave height in metre, the severity table provide details of the level of risk.

Tsunami probability of occurrences:

It is almost impossible to predict the exact reoccurrence of tsunamis similarly to earthquakes, seismic activity is the only significant trigger for tsunamis is to occur in the UAE. Forecasting the period might be difficult and the only best way is to use historical data available to support the assumption of probability values. In the UAE there is no tsunami specific monitoring program exists for the Arabian Gulf region. Based on the available historical records it is determined that the Arabian Gulf region has been occasionally subjected to tsunamis or to tsunami-like waves generated 
in the Indian Ocean. The following table indicates the most of the recorded tsunamis generated mainly in the Indian Ocean:

Table 1.11: Historical records of tsunamis that may have possibly affected UAE. Source: [17] and [18]

\begin{tabular}{|c|c|c|c|}
\hline Year & Location & Source & Description \\
\hline 326 & Southern & Unknown & Previous research has found that a large wave believed to be a tsunami \\
\hline B.C.E & Pakistan & & $\begin{array}{l}\text { destroyed the Macedonian Fleet in this area. This tsunami occurred in the same } \\
\text { region as that of the } 1945 \text { Makran tsunami. Therefore, it is believed that its } \\
\text { effects on the UAE would likely have been similar to the } 1945 \text { event. }\end{array}$ \\
\hline 978 & Siraf, Iran & Earthquake & The historical records show that the land shook for seven days. \\
\hline 1008 & Siraf, Iran & Earthquake & $\begin{array}{l}\text { The town fell into the sea. Although there is no mention that this event } \\
\text { generated a specific tsunami, } 30 \text { years later in } 1008 \text { and another earthquake } \\
\text { reportedly did. It was reported that a number of ships sank due to the high } \\
\text { waves generated by an earthquake occurring in this region. It is still unclear } \\
\text { what the cause of the high waves was. Some argue that it is possible that the } \\
\text { reported waves may have been generated by an earthquake triggered coastal } \\
\text { landslide. However, there are some data explain that the historical records do } \\
\text { not indicate that one occurred in conjunction with this particular event, or any } \\
\text { other earthquake in the Gulf region. }\end{array}$ \\
\hline 1524 & Dabul, India & Earthquake & $\begin{array}{l}\text { A large tsunami has been reported, but it is still unknown if this event occurred } \\
\text { only locally or regionally. The Makran region of Pakistan has been suggested } \\
\text { as a possible source. Based on the above, it is assumed that the eastern coasts } \\
\text { of the modern UAE would have likely been impacted by the tsunami as well. }\end{array}$ \\
\hline 1819 & $\begin{array}{c}\text { Gujarat, } \\
\text { India }\end{array}$ & Earthquake & $\begin{array}{l}\text { A large earthquake on } 1819 \text {, in the Kutch region of India, formed a destructive } \\
\text { tsunami. It is believed that the most likely area of the UAE to be affected } \\
\text { would have been its eastern coasts. }\end{array}$ \\
\hline 1883 & $\begin{array}{l}\text { Krakatau, } \\
\text { Indonesia }\end{array}$ & Volcano & $\begin{array}{l}\text { The sources reported a worldwide tsunami, with ships being affected as far } \\
\text { away as South Africa, and tide gauges registering it in London, England, and } \\
\text { San Francisco, California. }\end{array}$ \\
\hline Year & Location & Source & Description \\
\hline 1945 & $\begin{array}{l}\text { Makran, } \\
\text { Pakistan }\end{array}$ & Earthquake & $\begin{array}{l}\text { Strong earthquake estimated of } 8.1 \text { (Mw) was generated in the northern } \\
\text { Arabian Sea off of the Makran coast. The damage from the earthquake was } \\
\text { great, but the greatest destruction to the region was caused by a tsunami, which } \\
\text { was produced by the quake. The source stated that there are no direct records } \\
\text { of effects of this tsunami in the Gulf. However, it is widely believed now that } \\
\text { this tsunami did affect parts of the UAE. The rationale behind this new } \\
\text { thinking is the evidence of some morphological changes in Julfar, UAE. There } \\
\text { was a large sandbar at julfar, the forerunner of Ras Al Khaimah, over which } \\
\text { ships used transport goods. It was noted that sometime before 1964, this bar } \\
\text { was breached by a "tidal wave," which formed a direct channel from the open } \\
\text { sea to the harbour. }\end{array}$ \\
\hline 1983 & $\begin{array}{c}\text { Chagos } \\
\text { Archipelago, } \\
\text { Island of } \\
\text { Diego } \\
\text { Garcia }\end{array}$ & Earthquake & $\begin{array}{l}\text { Locally, the earthquake produced a } 1.5 \mathrm{~m} \text { tsunami. However, by the time this } \\
\text { tsunami reached Seychelles to the west, } 1,700 \mathrm{~km} \text { away, it was only } 40-\mathrm{cm} \text { in } \\
\text { height. It was determined that this tsunami had no impact on the UAE. }\end{array}$ \\
\hline 2004 & $\begin{array}{l}\text { Aceh, } \\
\text { Indonesia }\end{array}$ & Earthquake & $\begin{array}{l}\text { This event generated a large tsunami that affected the entire Indian Ocean } \\
\text { basin. It did not greatly impact the UAE, but it is indicated that the tsunami } \\
\text { produced small waves of } 3 \text { to } 30-\mathrm{cm} \text { in height along the UAE coasts. }\end{array}$ \\
\hline
\end{tabular}

The historical events are not accurate but they indicate some of the tsunami events have occurred. However the data is a useful guide to assume the probability values, engineering judgment should be made to set a logical sequence time. 
Table 1.12: Tsunami probabilities of occurrences

Probability of

Occurrence

Extremely Improbable $<3000$ Years

Low likelihood $<1000$ Years

Likely $<500$ Years

Highly Likely $<200$ Years

Near Certainty $<100$ Years

\section{Description}

Practically Impossible

This value was selected based on the historical data as the first record was almost 3000 years ago.

Very low chance of occurrence

1000 years gives a low likelihood of that an event can occur once in this time frame. This value is a typical value for engineering judgment.

Possible of occurring sometime

Every 500 years this period can be critical once evidence shows that it has happened around this period. Tsunamis just like earthquakes are unpredictable. Some historical data shows trend of 500 years event.

Some tsunami events has been recorded

Tsunami within this time range considers being critical.

Possibility of repeated tsunami events

If repeated records of tsunamis take place once every 100. This is considered to be an active seismic area.

\section{Tsunami risk matrix:}

Table 1.13: 5x5 Tsunami Risk Matrix

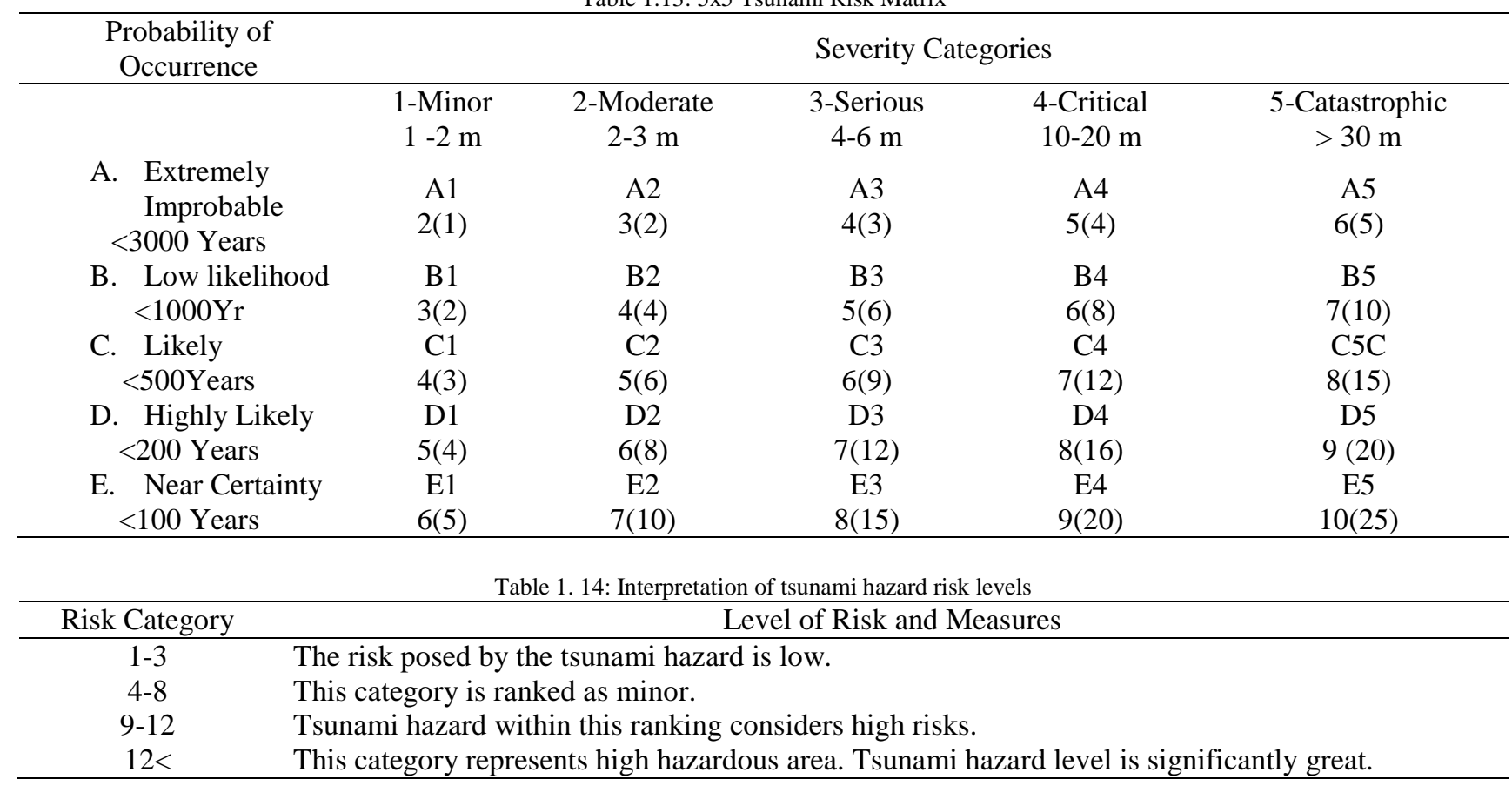

For the reasons of the susceptibility and risk analyses, a total of 5 values of probabilities have been selected with worst case and best case severity. The worst scenario represents highest tsunami wave that might happen in reality. This particular scenario is not applicable for the UAE, but the type of analysis requires such scenarios to be taken into consideration.

\subsection{Dust \& Sand storms risk}

UAE is well known for its susceptibility of DSS. There is no particular method of assessing the risk of DSS. The significance of such issue requires ample efforts to magnify the risks associated with this phenomenon. There is a significant distinction between dust and sand based on the particle diameter, the size of sand particle is $(0.08-0.015 \mathrm{~mm})$ and the dust is below $0.08 \mathrm{~mm}$ "De Villiers [8]". The criteria for defining DSS may vary from region to another and since the wind is the main factor that causes the DSS the optimum way is to define the wind speed first using knot unit. $1 \mathrm{knot}$ is approximately $=1.852 \mathrm{~km}$. The following table 1.17 shows the severity of consequences in regard to wind speed. 
Table 1. 15: Wind scale and its severity of consequences. Source: "[3]"

\begin{tabular}{lll}
\hline \multicolumn{1}{c}{ Knots } & \multicolumn{1}{c}{ Description } & \multicolumn{1}{c}{ Effects on land } \\
\hline $1-3$ & Light Air & Rising smoke drifts, wind vane is inactive. \\
$4-6$ & Light Breeze & Leaves rustle, can feel wind on your face, wind vanes begin to move. \\
$7-10$ & Gentle Breeze & Leaves and small twigs move, light weight flags extend. \\
$11-16$ & Moderate Breeze & Small branches move, raises dust, leaves and paper. \\
$17-21$ & Fresh Breeze & Small trees sway. \\
$22-27$ & Strong Breeze & Large tree branches move, telephone wires begin to "whistle", umbrellas are difficult to \\
& & keep under control. \\
$28-33$ & Moderate or & Large trees sway, becoming difficult to walk. \\
& Near Gale & Twigs and small branches are broken from trees, walking is difficult. \\
$34-40$ & Gale or Fresh Gale & Slight damage occurs to buildings, shingles are blown off of roofs. \\
$41-47$ & Strong Gale & Trees are broken or uprooted; building damage is considerable and reduced visibility. \\
$48-55$ & Whole Gale or Storm & Extensive widespread damage, visibility further reduced. \\
$56-63$ & Violent Storm & Extreme destruction, devastation, little visibility. \\
$64+$ & Hurricane &
\end{tabular}

Using the definition of DSS which is "A collection of particles of dust or sand, vigorously lifted to a great height by strong and turbulent wind and the vision is reduce by 1000 metres", dust begins to be lifted at wind speed of 15 knots and 20 knots to lift a sand particles [8]. Dust is more likely to be found around inhabited where human activities tend to break the sand into finer particles [8]. The aridity and low precipitation rate contribute significantly to suspension of sand and dust into the air for longer period.

Since the probability of occurrences is very high in comparison with the discussed natural hazards, the analysis will concentrate on a short historical data obtained by Abu Dhabi International Airport ADIA. The data will be presented based on the wind direction during the period 1994-2003 when the visibility was reduced below 5000 m:

Table 1. 16: Dust events and sand storms based on wind direction [8].

\begin{tabular}{cccc}
\hline Wind Direction & Dust Events & Dust/Sand storms & Total \\
\hline SE-WSW & 83 & 12 & 95 \\
W-NNW & 33 & 9 & 42 \\
N-ESE & 25 & 11 & 36 \\
Total & 141 & 32 & 173 \\
\hline
\end{tabular}

The events were divided into 3 different groups according to where the wind comes from:

1) SE-WSW: South East to West South Westerly

2) W-NNW: West to North-North West

3) N-ESE: North to East-South-East

The reason of these groups is that wind from SE to WSW blows from desert areas, wind from W to NNW blows from the length of Arabian Gulf and wind from N to ESE blows mainly from Iran side or gulf of Oman. The characteristics of winds differ according to direction of the wind where the worst wind comes from SE to WSW the visibility is often reduced because it has a long track off the desert areas. The W-NNW wind usually referred as "Shamal" is categorized to be the primary cause of DSS, the fine clay particles in Iraq and Iran are carried away by Shamal travelling over large area of Middle East including the UAE.

The visibility is less reduced when the wind comes from W to ESE along the Arabian Gulf comparing to the SE-WSW wind and W-NNW. The wind comes from N to ESE is more frequent and more difficult to categorize; it depends on the wind speed and its ability to carry off sand and dust, most of the time the wind is not strong enough to lift sand and dust particles over the land. Once this type of wind has a higher momentum then more DSS is expected, the short historical data considers only the wind speed of 15 knots and above [8].

Typically there are three different synoptic situations have been found to be the cause of DSS in the region, during the winter months, DSS occur either before or after the passage of a cold front. In the summer months, the north westerly winds "Shamal" are the primary mechanism for dust DSS.

In reference to number of events according to the table, it can be seen that most of the DSS events occur when wind comes from SE-WSW which is usually associated with strong wind. In winter season winds can gust up to 60 knots, the wind direction is typically between the west and north. In summer season some thunderstorm activities over the north eastern mountains can lead to an eastern approaching gust front with average wind speed of 40 to 50 knots, these gusts are short lived and the wind soon decreases to around 20 to 28 knots [19].

Based on the above analysis, the result can be drawn that the wind speed is the main factor for DSS in respect to aridity and source of sand and dust. Lack of the natural vegetation and the increase the industrial activity attributes to the 
occurrence of DSS. It difficult to characterize the DSS in terms of their frequency, basically a strong wind which is able to lift sand particles can cause DSS.

\subsection{Climate change risk}

Many views on the issues of climate change have been raised; different parts of the world have evidenced the phenomenon. Assessing the risk posed by climate change is challenging since the historical data is not enough to support a clear projection of the climate change impact. The assessment will cover the aspects of sea level rising, precipitation rate and recent cyclones.

The sea level rising is more or less global issue due to increase temperatures on the earth because of glaciers melting. Latest measurement by satellite has indicated that global mean sea level has risen around 10-20 cm in the past century. The annual increase over the past 20 years has been 3.2 millimetres a year. According to published study done by Chowdhury, there are three levels of climate change which the UAE can be affected:

1) Global warming phenomena which can increase the temperature in UAE up to 5.8 degree Celsius by year 2100 due to carbon dioxide sheet getting thicker.

2) Areas which are susceptible to flooding have some severe flooding while other areas are dry.

3) Sea level rising which has affected some environmental aspects. [25].

The three levels above follows the global pattern of climate change, there are many predictions and scenarios for weather patterns and the most logical pattern suggest that the climate in the Middle East will become hotter and drier.

The recent severe cyclones that struck the neighbour country of UAE "Oman" (Gonu) 2007 and (Phet) 2010 has raised the issue of the climate change and their link. The super cyclone Gonu made landfall on the easternmost tip of Oman with winds of $41.7 \mathrm{~m} / \mathrm{s}$. Cyclone Gonu was the strongest tropical cyclone on record to hit the Arabian Peninsula "[28]". The northern and eastern sections of the UAE experienced strong wind and rainfall, the influence of Gonu was not felt in the western region of the UAE.

Most of the studies conducted so far are uncertain on the possible changes in occurrence of cyclones. It is almost certain that an increase in sea surface temperature will be associated by a corresponding increase in cyclone strength. Recent studies suggest a possible increase in cyclone intensity of $10-20 \%$ for a rise in sea [26]

Sea level rise seems to be the most significant aspect of climate change. It is linked to global warming so far there are no models that project the future impact of climate change. Sea level rise might be distributed evenly along the coast of UAE but the only climate change aspect that can make a difference is the intensity of the cyclones that could be more on the eastern region.

\section{Results \& discussion}

The information focuses on the primary hazards identified followed by risk assessment which highlights some of the natural hazards risk in the UAE. The risk matrices method was used to scale the risk based on scoring, the approach is straightforward to generate risk maps based on it. However other hazards were not analysed based on risk matrices, the results will be discussed in form of context. Hazard maps are important tools to show information of hazards, vulnerabilities and risks in a specific region and thus support the risk assessment; the hazard maps are helpful to characterize the hazardous zones in comparison of other locations. Generally the perceived risks of natural hazards have the trend of being greater on the eastern and north eastern region of the UAE.

\subsection{Seismic hazard map}

A Hazard map is a summary of the results obtained from the risk matrix that was conducted for seismic. The following figure 1.17 shows the seismic hazard map corresponds to 475 years return period. As might be expected, the areas of highest seismic activity are the areas where earthquakes have been most common in the past. 


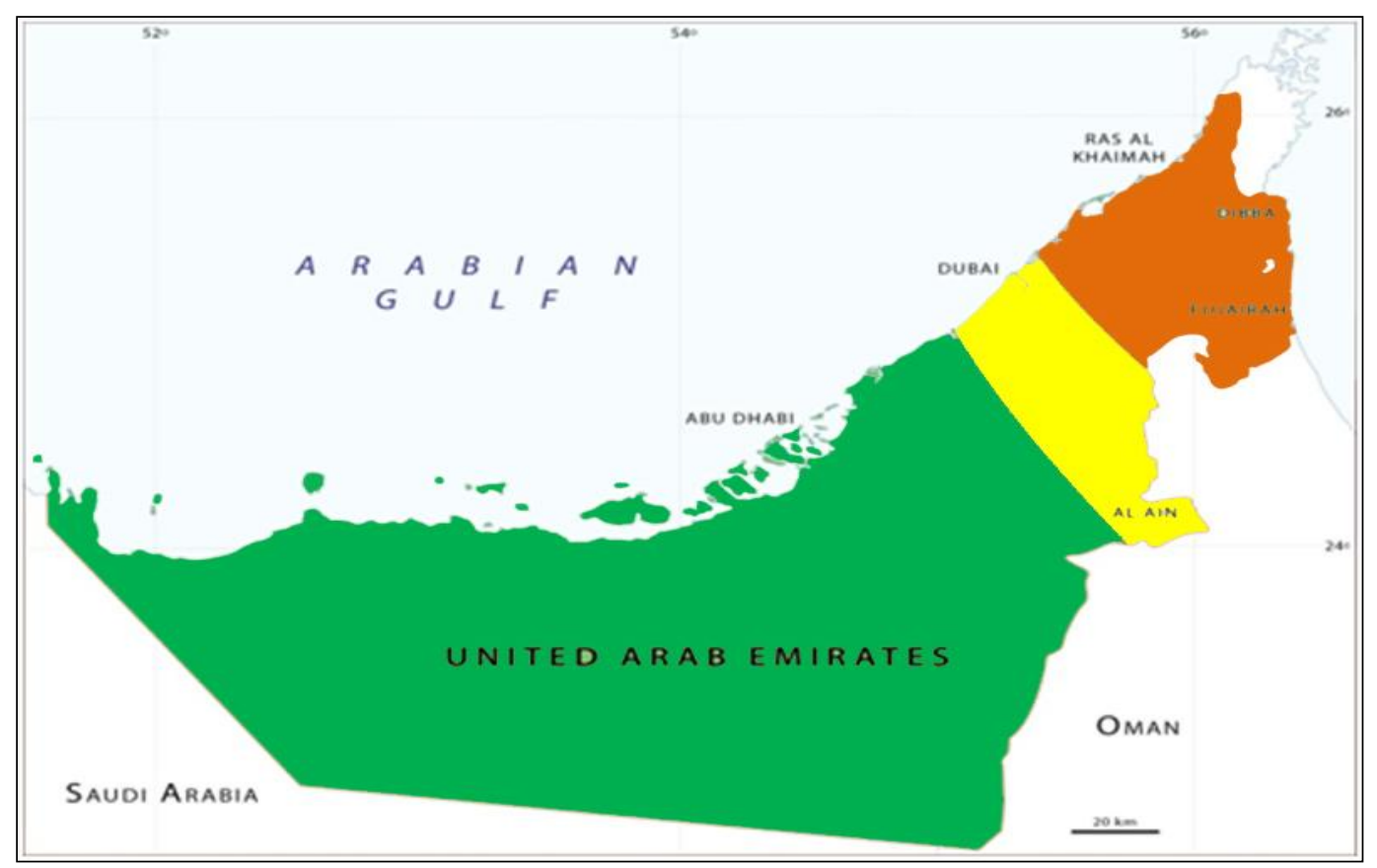

Figure 1.4: UAE Seismic Hazard Map

The brown zones show a higher seismic risk than averages encompass the north and north eastern parts of the UAE. The actual values of earthquake intensity degrade down as moving to the south west and south east where shown by yellow and green colours. This is because of the subsurface rock distribution which provides high conductive medium for the seismic waves the solid rocks get deeper as moving toward the south western areas.

The study indicates that large area of the UAE could be classified as safe zones shown in the green where the PGA is less than $0.039 \mathrm{~g}$. The UAE is exposed to a level of seismic risk; the PGA values are relatively small in comparison with seismic events in other parts of the world.

\subsection{Tsunami hazard map \& climate change}

From the overall result of tsunami risk assessment, it is evident that the greatest tsunami risk facing the UAE comes from sources in the Indian Ocean and the greatest potential tsunami source most likely to be earthquakes. Climate change effects is hard to predict since its global issue that has a clear evidence on sea level rising, the only applicable impacts of climate change on UAE are the increase of the temperatures and sea level rising. The sea level rising measurement is not accurate in the UAE but as indicated in literature review there is some parts in the UAE especially where the artificial islands are going to be affected. Hence the Arabian Gulf depth does not support the tsunami even with forecasted future scenario for sea level rising it will not support coastal flooding as it will not reach to greater depth where tsunami needs to develop its intensity.

Since the tsunami hazard is linked to seismic activity the northern and north eastern areas of the UAE is subjected more to tsunami. The evidence was clear from the historical record that Arabian Gulf is almost risk free zone from tsunami excluding the northern part close to the Indian Ocean. The yellow zone shows the areas that can be vulnerable to tsunami more. The small area in the north western part is highlighted in yellow because of the possibility of deflected waves as a result of tsunami event in the Indian Ocean.

The threat posed by tsunami to the UAE showed that there are minor chances of possible tsunami occurrences especially in the yellowish region according to the map. Though there are rare possibilities in which seismic activity could generate tsunami-in the Arabian gulf where shown in the green region. The tsunami type events are unlikely to exceed the anticipated severity especially in the green areas according to physical properties of the Arabian Gulf. 


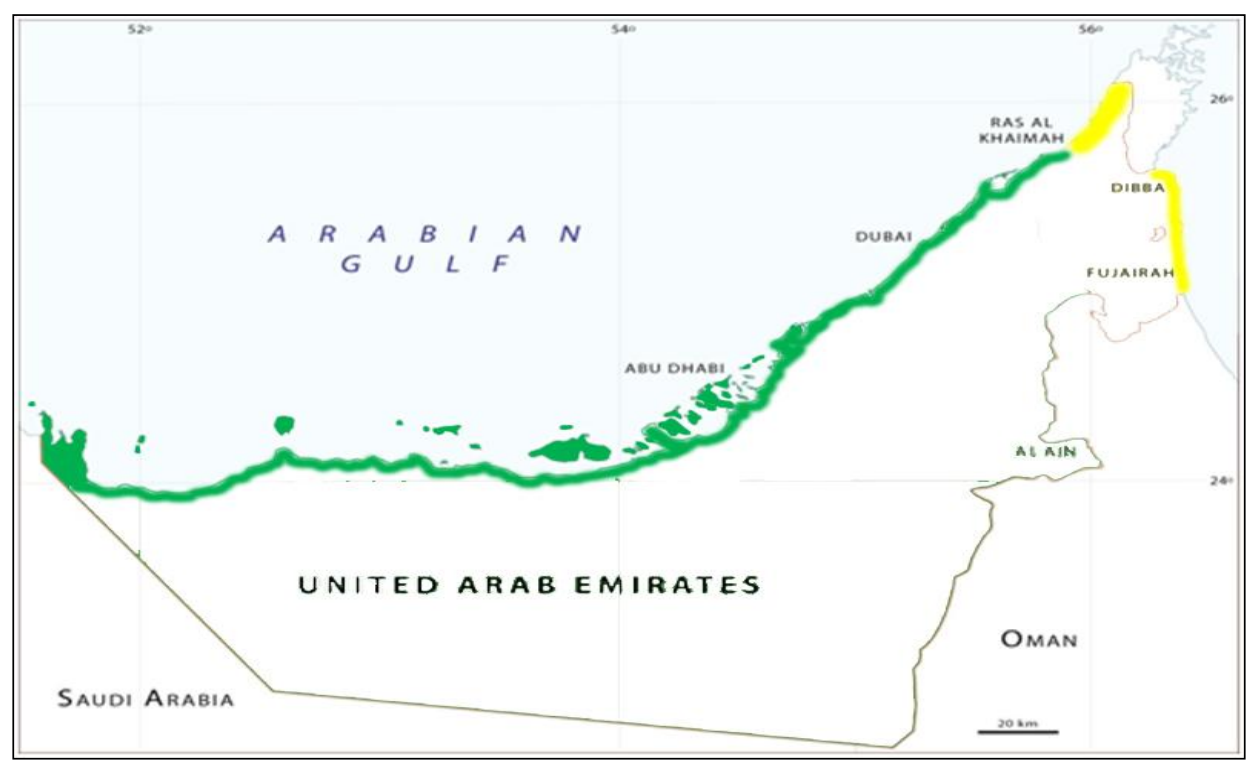

Figure 1. 5: UAE Tsunami Hazard Map

\subsection{Flooding hazard map}

The extent flood hazard maps depicts areas susceptible to flooding, although the UAE has a lack of precipitation but some other causes are presented and considered in the hazard map. Flood hazard map was based on the risk matrix taking into considerations the causes such as the occasional surface water and localized Sabkhas excluding the coastal flooding which was discussed in tsunami section.

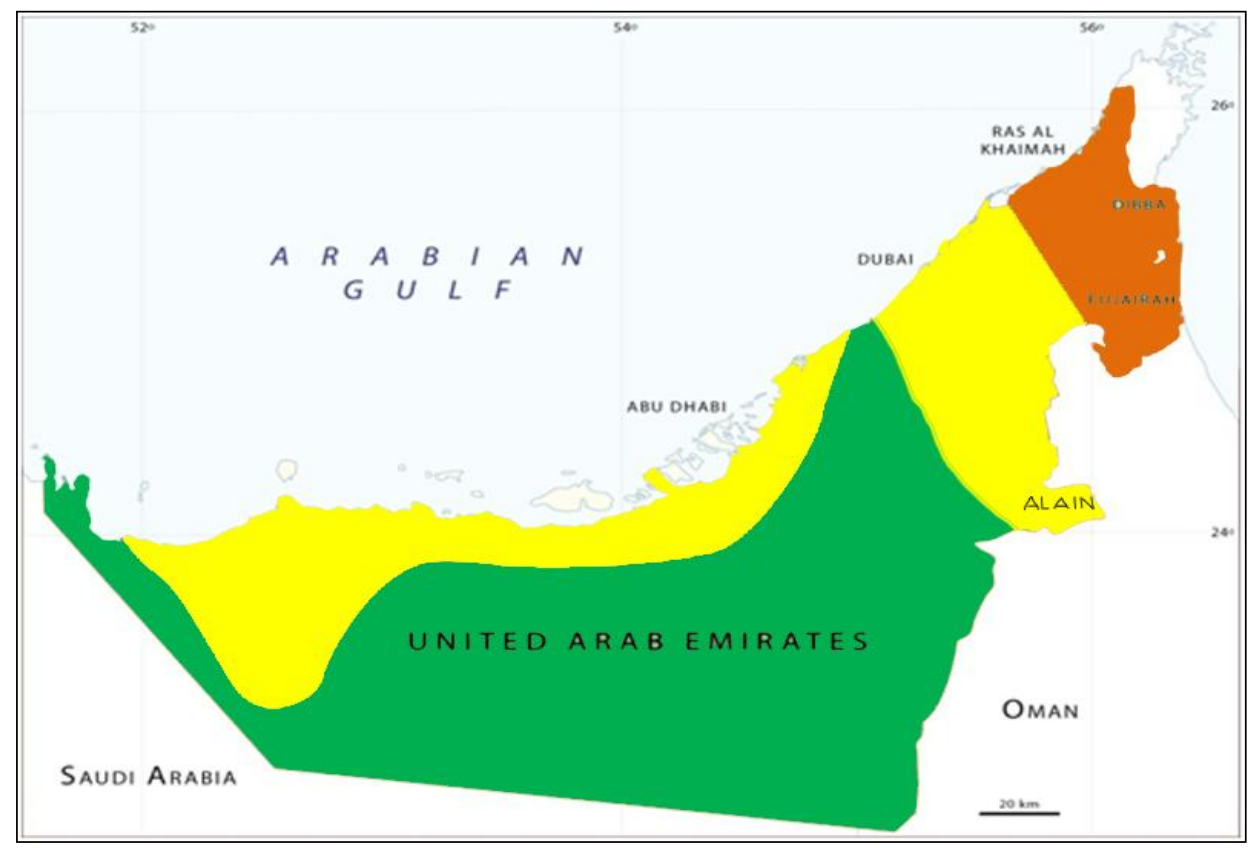

Figure 1.6: UAE Flooding Hazard Map

There is clear variation of risk levels as shown in the flooding map, it is obvious that the north and north eastern parts have a higher risk levels indicated by the green region. This is mainly due to higher precipitation rates and "Wadies". Mountian areas in the northern parts have less infiltration rates the runoff possibility is higher comparing to the desert zones. Some major wadies pathways cover the north region indicated by the brown zones however some areas might not be subjected to flood. The yellow regions which cover the cities Alain and Dubai are vulnerable to flood due to wadies pathways as well but since the infiltration rates are higher comparing to the northern parts the runoff water don't last for longer periods. The yellow region in the western part especially on the coastal areas is subjected to flood because of the sabkhas flats which exist there. 
To accommodate the uncertainty of the flood hazard map, the consideration of annual precipitation rate and Sabkhas flooding have been taken into account. The brown colour area has more potential of flooding because of wadies and mountains that promote the surface flood. The yellow areas are a mix of low flat areas with some topographical highs that has both Sabkhas and small Wadie systems. Thought the flooding hazard is rare in the UAE, big events are unlikely especially flooding from Sabkhas as it may require heavy precipitation.

\subsection{DSS hazard map}

The most serious natural hazards existed in the UAE are the DSS, the analyses was carried out to identify the source of winds that trigger the DSS. One of the sand and dust sources as mentions is the largest mobilized sand dunes area "Empty Quarter". The graphical representation of the map indicates the wind direction based on their level of risk as showing in the following figure 1.20:

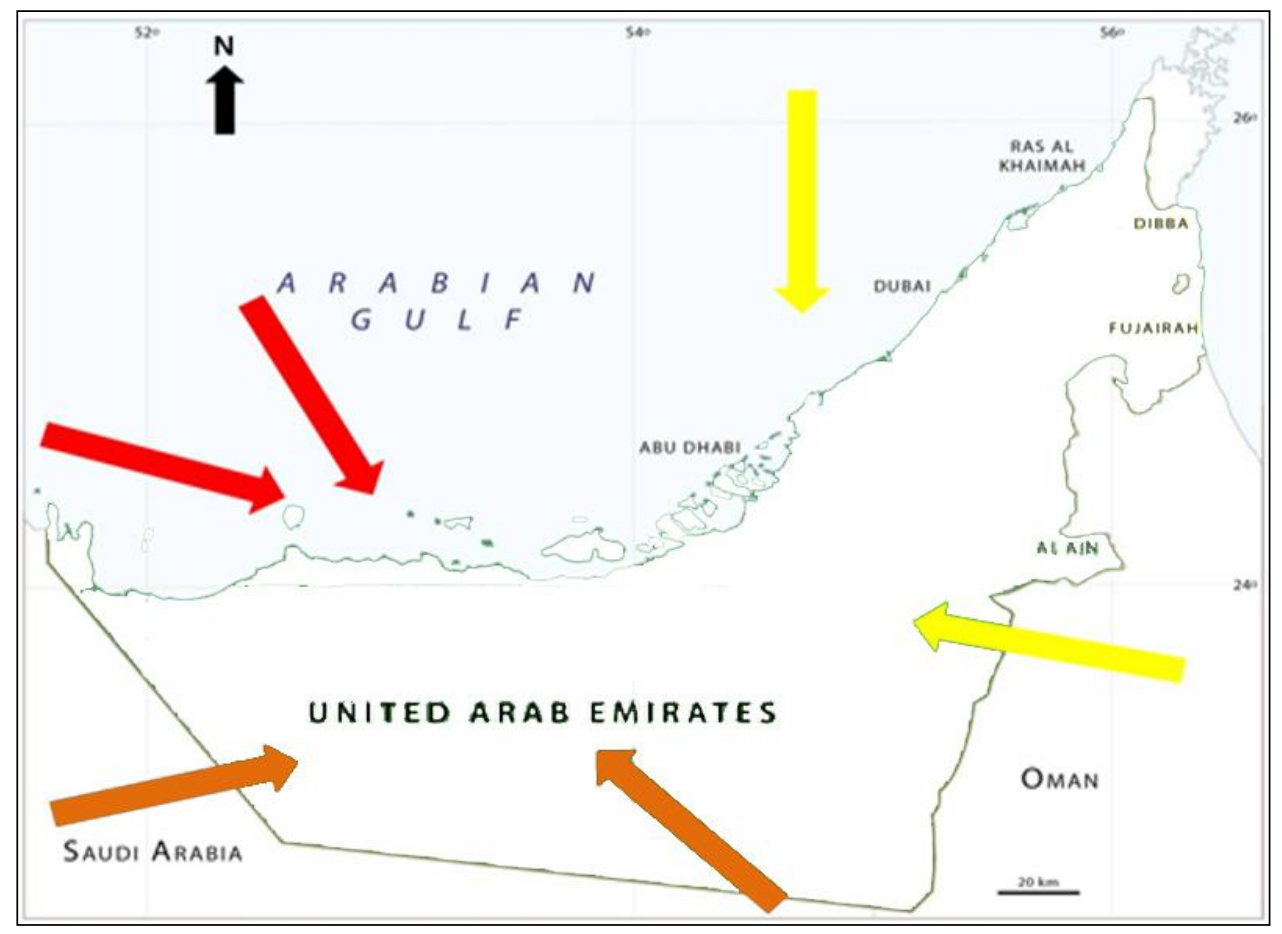

Figure 1.7: UAE DSS Hazard Map

As depicted in the hazard map the types of winds based on their directions, the yellow arrows indicate the less intensity winds come from north to south and east to west. Then brown arrows indicate more hazardous winds south to west and south west to east since they pass by the "Empty Quarter". Finally the most hazardous winds come from Iraq and Iran which have high intensity as indicated by the red arrows.

The risk is posed by the low visibility caused by the winds, "Shamal" represents by the red arrows considered the most critical winds as they usually come with high intensity 15 knobs and above. There is no clear evidence that some parts have less exposure of DSS than other areas, it usually spreads all over the areas with minor intensity differences.

\subsection{Multi hazard map}

The summation of natural hazard is critical to view the overall discussed information of the related hazards. The final results show that seismic, flooding, tsunami, climate change and DSS pose serious threats to the very north east part of the UAE as showing in the following figure 1.21:

The highest risks by far throughout all of the analyses are caused by seismic risk and tsunami since they have been characterized as critical natural hazard. Although some other hazards are much more frequent i.e. DSS according to historical data "refer to table 1.1. Larger area of the UAE falls within the green area which almost insignificant risks, even though within the risk assessment form is called insignificant risk but they should be reviewed as well.

The multi-hazard map generated from this study is a combination of literature review, historical data and risk matrix. From the hazard evaluation the information was perceived based on probability of occurrence and severity of consequences for each disaster. 
The consideration of regional risk profiles in the UAE reflects ideal environmental conditions especially in the west part where less natural hazards occurrences in comparison to north eastern parts. The biggest challenge remains the lack of historical data for some specific hazards data, but the overall risk assessment shows a single common trend that can be used as primary study.

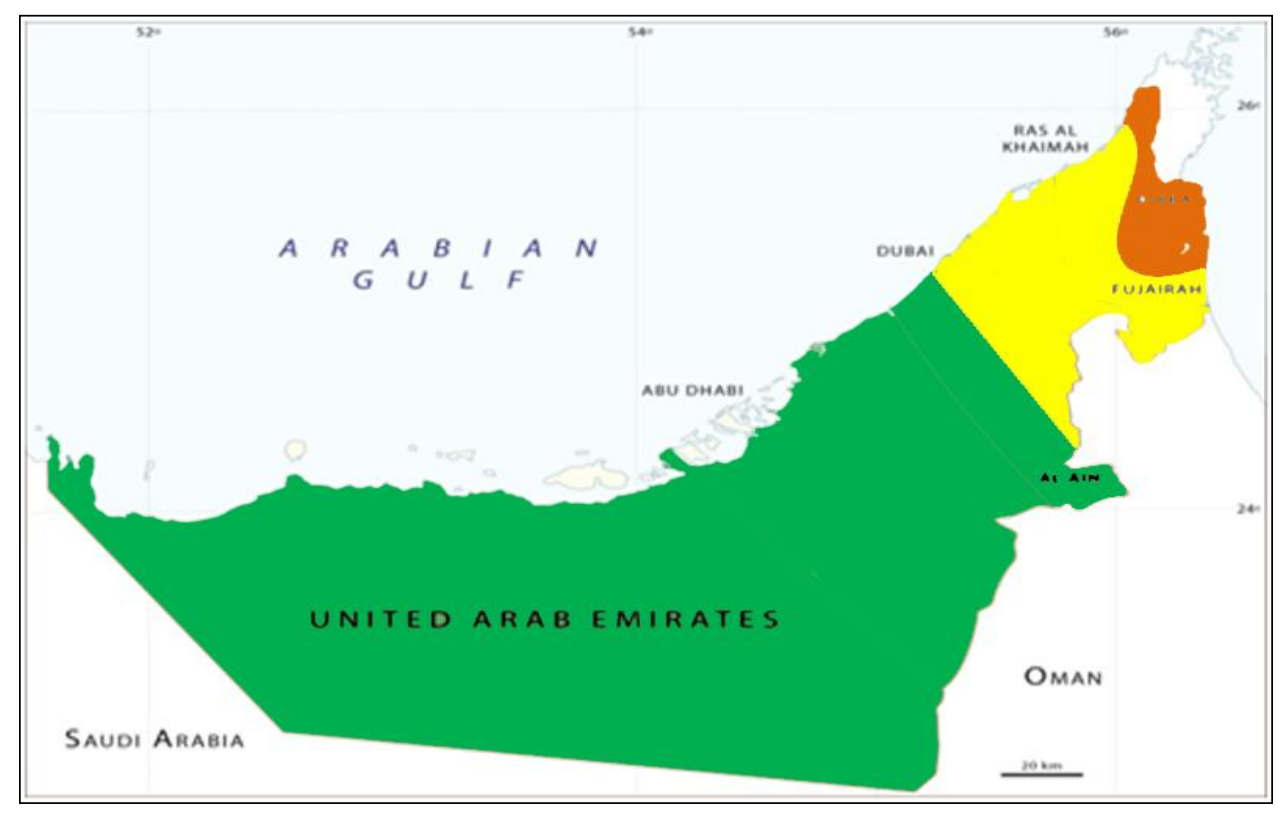

Figure 1.8: UAE Multi-Hazards Map

\section{Conclusions \& recommendations}

Based on the aims and objectives of the study the following hazards were discussed which formed the reasons for selecting the former specific hazards:

1) Seismic activity

2) Tsunami

3) Flooding

4) DSS

5) Climate change

The data collection was based on reports, scientific research and historical data. Moreover, the literature review has covered some previous studies done for the related natural hazards in the UAE. The historical records for the UAE are limited to information that is obtainable from academic published reports and governmental records. Engineering judgments were used to fill gaps due to lack of historical data.

Risk matrices were conducted to assess the natural hazards in the UAE; the method allows quantitive and qualitative analysis with comparison of risk level between UAE and the rest of the world. Climate change and DSS hazards were assessed differently due to their characteristics.

As described earlier the geology section of the UAE mainly consists of sand dunes in the central and western parts where northern and north eastern parts have mountain series. The geographical and geological variations have impacts on the level hazards distribution in the country. Based on the risk assessment results the highest hazardous region is located in the north and north eastern parts. The central and western regions show relatively lower levels of risk this is only applied for all hazards excluding the DSS which usually strikes regionally based on the wind direction.

Results were presented as individual hazard maps for all hazards discussed and were combined for tsunami and climate change since it is linked to sea level rising. At the end a multi-hazards map produced as result of all hazards mapped, it gives an indication of the overall hazards. However the study has identified regions that have lower risk and for which the recommendations shall be stated:

- Natural hazards have varying degrees of uncertainty in terms of their probability of occurrences and their severity, the study has combined historical data and engineering judgments that are driven from the available reports. Historical data needs a long time to be obtained but meanwhile the engineering judgment is an option once they are based on reliable information. 
Through the research study there might be additional efforts to be done in gathering historical data even from nearby countries. As indicated by the study the risk assessment has contained substantial amount of data to result hazard maps but the shortage of recorded data of climate change influence was only addressed in association with tsunami.

\section{References}

[1] United States Geological Survey USGS, 2003. Geological Hazards Science Center. [online] available at: https://geohazards.usgs.gov/ [Accessed 28, April 25, 2012]

[2] HSE,2005“REVIEW OF HAZARD IDENTIFICAION TECNIQUES” [online] available at: www.hse.gov.uk/research/hsl_pdf/2005/hs10558.pdf [Accessed 28, April 2012]

[3] National Oceanic and Atmospheric Administration USA, NOAA, 2010. U.S Flood. [online] available at: http://www.noaa.gov/ [Accessed 30, April, 2012]

[4] Ambler, H 2003 Environmental Security and Global Stability. Problems and Responses. Parametres. \{E-journal \} Vol. 33. Issue: 4. available through Questia online library, [Accessed 6, May, 2012]

[5] H. Baker, 2008. Tsunami hazards along the coasts of the United Arab Emirates. [online] available at: www.iahr.net [Accessed 14, May, 2012]

[6] Rodgers, 2005.Seismic Monitoring for the United Arab Emirates. [online] available at: http://www.osti.gov/ [Accessed 15, May, 2012]

[7] Kazmi, 2011. Seismic activity 'not worrisome'. [online] available at: http://gulfnews.com/news/gulf/uae/general/seismic-activity-notworrisome-1.765673 [Accessed 18, May, 2012]

[8] De Villiers, 2005.Dust Storms in Abu Dhabi. [online] available at: www.onlinelibrary.wiley.com/doi/10.1002/wea.42/pdf [Accessed 21, May, 2012]

[9] World Health Organization, 2007.Flood Hazard Distribution Map. [online] available at: www.emro.who.int/eha/pdf/are_flood.pdf [Accessed 18, May, 2012]

[10] USGS, 2010. Geological Hazard Science Centre. [online] available at: https://geohazards.usgs.gov/deaggint/2002/documentation/parm.php [Accessed 30, May, 2012]

[11] USGS, 2011. Earthquake Hazards Program. [online] available at: http://earthquake.usgs.gov/earthquakes/shakemap/background.php\#intmaps [Accessed 2, Jun, 2012]

[12] Arabia. 2012. Encyclopaedia Britannica. [online] available at: http://www.britannica.com/EBchecked/topic/31551/Arabia/45278/Geology[Accessed 8, Jun, 2012]

[13] Jamal A. ABDALLA and Azm AL-HOMOUD, 2011. Earthquake hazard zonation of Eastern Arabia. [online] available at: www.iitk.ac.in/nicee/wcee/article/13_1008.pdf [Accessed 2, Jun, 2012]

[14] G.W. Hughes, "The Great Pearl Bank Barrier of the Southern Arabian Gulf - A Possible Analog for the Aptian Rudist Banks of the Arabian Peninsula," Quaternary Deserts and Climatic Change, (Ed. by A.S. Alsharhan, K.W. Glennie, G.L. Whittle, et al.), pp. 565- 582, Balkema, Rotterdam, 1998.

[15] European Commission, 2010. Risk Assessment and Guidelines for disaster management. [online] available at: http://register.consilium.europa.eu/pdf/en/10/st17/st17833.en10.pdf [Accessed 2, Jun, 2012]

[16] Vanessa Cançado*, Lucas Brasil, Nilo Nascimento, André Guerra, 2008. Flood risk assessment in an urban area: Measuring hazard and vulnerability [online] available at: www.web.sbe.hw.ac.uk/staffprofiles/bdgsa/11th...on...CD/.../699.pdf [Accessed 4, Jun, 2012]

[17] Jordan, 2008. "Tsunamis of the Arabian Peninsula: A Guide of Historic Events," Science of Tsunami Hazards, Vol. 27, No. 1, page 31, United Arab Emirates University. [online] available at: http://tsunamisociety.org/271Jordan.pdf , [Accessed 7, Jun,2012]

[18] R. Jordan, 2008. "Tsunami Hazards and Mitigation along the Coasts of the United Arab Emirates," Department of Geology, United Arab Emirates University. [online] available at: http://emp.byui.edu/JordanB/PDFs/Abstract6.pdf [Accessed 9, Jun, 2012]

[19] J. Kämpf and M. Sadrinasab, "The Circulation of the Persian Gulf: A Numerical

[20] Study," Ocean Science, No. 2, pp. 27-41, Copernicus GmbH, Germany, July 2006

[21] Alastair Dale, Ruth Goodall and Marc Pinnell. 2008. Flood Probability. Do we know enough about it or does it just confuse the issue? [online] available at: www.hydrology.org.uk/Publications/exeter/48.pdf [Accessed 15, Jun, 2012]

[22] G.A. Cooper, R.J. Falvey, “1975-2008 Annual Tropical Cyclone Report,” ed. by M.Vancas, Chapter 2, United States Naval Maritime Forecast Center/Joint Typhoon

[23] Warning Center, Pearl Harbor, Hawaii, 2008.

[24] Vijay.P. Singh. "Water resources system operation" Water and Environmental, No. 1, pp. 31-33, Mumbai, 2003

[25] Chowdhury F, 2010. Climate change. [online] available at: http://www.khaleejtimes.com/DisplayArticle.asp?xfile=data/theuae/2010/December/theuae_December652.xml\&section=theuae\&col [Accessed 20, Jun, 2012]

[26] William W. Dougherty, 2009. Climate change impact, vulnerability and adaption. [online] available at: www.sei-us.org/...PDF/SEI-EAD ImpactVulnerabilityAdaptation-09.pdf [Accessed 29, Jun, 2012]

[27] Congressional Research Service CRS, 2009. The United Arab Emirates Nuclear Program and Proposed US Nuclear Regulation. [online] available at: www.fpc.state.gov/documents/organization/135951.pdf [Accessed 4, Jul, 2012]

[28] Latfy, 2007. Using remote sensing and GIS for damage assessment after flooding, the case of Muscat, Oman after Gonu tropical cyclone 2007: Urban planning perspective. . [online] available at: www.corp.at/archive/CORP2010_182.pdf [Accessed 4, Jul, 2012]

[29] Yeon-Sik Kim *, Ki-Yong Choi, Hyeon-Sik Park, Seok Cho, Bok-Deug Kim, Nam-Hyeon Choi, Won-Pil Baek. 2008. Commissioning of the ATLAS thermal-hydraulic integral test facility. [online] available at: www.ewp.rpi.edu/hartford/ ernesto/F2011/EP/.../Kim2008.pdf [Accessed 17, Jul, 2012]

[30] Sylvia Szabo, 2011. The Water Challenge in the UAE. [online] available at: www.dsg.ae/en/Publication/Pdf_En/127201212127404843750.pdf [Accessed 30, Aug, 2012]

[31] Richard Walker, 2005. A remote sensing study of active folding and faulting in southern Kerman province, S.E. Iran. [online] available at: http://oxford.academia.edu/RichardWalker/Papers/1159463/A_remote_sensing_study_of_active_folding_and_faulting_in_southern_Kerman_ province_SE_Iran [Accessed 31, Aug, 2012]

[32] Jack Watson, Leland Hardy, Tom Cordell, Susan Cordell, Ed Minch and Carl Pachek. 1995. How Water Moves Through the Soil. [online] available at: gcrec.ifas.ufl.edu/Shober/Water\%20Movement\%20Guide.pdf [Accessed 31, Aug, 2012] 